\title{
REJECTION RATES FOR JOURNALS PUBLISHING IN THE ATMOSPHERIC SCIENCES
}

\author{
BY DAVID M. SCHULTZ
}

The most-cited journals do not necessarily have the highest rejection rates.

W hat controls the rate at which manuscripts submitted to a scientific journal for publication are rejected (hereafter, the rejection rate)? Because the rejection rate of a journal is the number of rejections divided by the number of submissions, factors that affect either the number of rejections or the number of submissions will affect the rejection rate (see the sidebar "Factors that affect rejection rates at journals"). Specifically, these factors will depend upon the authors, reviewers, journal, and editor (Table 1).

Much effort has tried to raise the quality of scientific publications, as noted by the number of books available for authors to improve their ability to communicate scientific and technical information (e.g., Perelman et al. 1998; Montgomery 2003; Day and

AFFILIATIONS: SCHULtZ-Division of Atmospheric Sciences and Geophysics, Department of Physics, University of Helsinki, and Finnish Meteorological Institute, Helsinki, Finland CORRESPONDING AUTHOR: Dr. David M. Schultz, Finnish Meteorological Institute, P.O. Box 503, Erik Palménin Aukio I, FI-00I0I Helsinki, Finland

E-mail: david.schultz@fmi.fi

The abstract for this article can be found in this issue, following the table of contents.

DOI:10.1175/2009BAMS2908.1

In final form 7 September 2009

(2)2010 American Meteorological Society
Gastel 2006) and the number of books and articles by journal editors pleading for an improved quality of submitted manuscripts (e.g., Batchelor 1981; Lipton 1998; Thrower 2007; Schultz 2009b). However, only a limited number of studies have investigated the rejection rates at journals as a matter of publication policy [chapter 2 in Weller (2001) provides an excellent review], and none has investigated atmospheric science journals specifically.

For example, Zuckerman and Merton (1971) examined rejection rates in 83 science and humanities journals, finding that the rejection rates in humanities and social science journals were higher than those in physical science journals (more than $70 \%$ compared to about $30 \%$ ), a result later confirmed by Miller and Serzan (1984). Zuckerman and Merton (1971) attributed these disciplinary differences to the amount of available space in the journal and to consensus, a measure of the shared "conceptions of appropriate research problems, theoretical approaches, or research techniques" (Hargens 1988). Hargens (1988) examined 30 journals in the late 1960s and again in the early 1980s and found little evidence to support the available-space argument, principally because the rejection rates of the journals had not changed much during this time despite changes in the number of submissions. Instead, Hargens (1988) attributed differences in rejection rates to differences in consensus among the different disciplines. 
The purpose of the present article is to understand what factors affect the rejection rates at atmospheric science journals. I avoid the cross-disciplinary focus of previous research by focusing specifically on journals that publish articles on atmospheric science, either wholly or partially. By focusing on a specific discipline, the effect of consensus can be minimized because consensus among atmospheric scientists is likely to be greater than consensus among different scientific disciplines. Doing so should clarify the factors that affect rejection rate within a discipline.

DATA. The dataset was constructed in two steps. First, an initial list of atmospheric science journals was obtained online from the Institute of Scientific Information (ISI) Web of Knowledge, Thomson Reuters (online at www.isiwebofknowledge.com). Their 2006 journal summary list under subject category "Meteorology \& Atmospheric Sciences" ranked 48 journals. An additional 15 journals were added to this list, encompassing ISI-ranked journals that atmospheric scientists may publish in outside of the "Meteorology \& Atmospheric Sciences" category; unranked journals published by the American Geophysical Union (AGU), American Meteorological Society (AMS), European Geosciences Union (EGU), and National Weather Association (NWA); and other atmospheric science journals not ranked by ISI. All 63 of these journals may publish exclusively or partially on topics within the atmospheric sciences.
The second step was to contact the editors, editorial assistants, or publishers of these 63 journals to obtain publication statistics. I conducted the survey by e-mail between 13 November 2006-15 May 2008 and 29 April 2009-1 May 2009. AGU journals (GBC, GRL, JGR-Atm, RS, SW; see Table 2 for a list of the journal abbreviations used in this article) provide some data in a graphical format online (www.agu. org/pubs/stats), so I estimated the numbers of manuscript submissions and published articles from the graphs, calculating the approximate rejection rates. One journal allowed me to use their data but not disclose their name; hereafter, this journal is referred to as Unnamed. Four journals responded that they do not publicly provide statistics on rejection rates [Climate Research (CR), Journal of Atmospheric Chemistry, Tellus A, and Tellus B). Three journals promised but did not deliver their data (Atmósfera, Earth Interactions, and Journal of Atmospheric and SolarTerrestrial Physics). Nine journals did not respond to my e-mailed requests to share their rejection rates [Agricultural and Forest Meteorology (AFM); Annals of Geophysics; International Journal of Climatology; Izvestiya, Atmospheric and Oceanic Physics; Journal of Lightning Research; The Open Atmospheric Science Journal; Physics and Chemistry of the Earth; Science; and Water, Air, \& Soil Pollution].

Unfortunately, journals that publish articles from disciplines in addition to atmospheric science (e.g., $E F M, G, G R L)$ do not separate their rejection rates by discipline, except for AO, JAOT, and Terrestrial,

\section{FACTORS THAT AFFECT REIECTION RATES AT IOURNALS}

Come of the many factors that affect the rejection rates

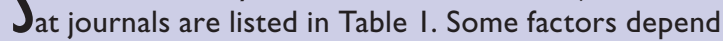
upon the authors who submit the manuscripts: submission of manuscripts on an inappropriate topic to a journal, the author's ability to conduct publishable science, which in turn is a factor of the author's educational level, professional experience, affiliation, and country of origin, etc. (e.g., Bakanic et al. 1987; Opthof et al. 2002). Other factors depend upon the quality and experience of the reviewers picked by the editor, with some reviewers more likely to recommend rejection than others (e.g., Siegelman 1991; Opthof et al. 2002).

Some factors depend upon the journal: its reputation, its breadth, its exposure to attract potential submissions, the quality of its submissions, the peer-review process, whether reviewers are anonymous, and how many submissions they receive versus the number of pages they can afford to publish. Specifically, the editorial policy of some journals is to regulate their submissions, with varying degrees of intensity, by rejecting high-quality manuscripts whose content is deemed too specific or too off-topic for the journal. Journals in part set the policy for their rejection rates through their form of peer review. This statement is evidenced by the editorials that often herald changes in rejection rates (particularly when they increase) when journal policies change (e.g., Koshland 1985; Drummond and Reeves 2005; Famiglietti 2007). Specifically, the policy of some journals is to reject manuscripts that require more than minor revisions to keep time to publication short and the quality high (e.g., Famiglietti 2007).

Finally, the editors - the people who decide to reject or accept based on reviewer recommendations-clearly affect the rejection rate. Specifically, a simple physical model (Schultz 2009a) can explain the editor rejection rate as a function of the probability of reviewers recommending rejection, the number of reviewers, and the editor's decisionmaking strategy (i.e., reject when at least one reviewer recommends rejection, reject when a majority of reviewers recommend rejection, reject when all reviewers recommend rejection). 
Atmospheric and Oceanic Sciences (TAOS). AO and JAOT have separate atmosphere and ocean sections handled by different cochief editors, each maintaining separate statistics, so the two sections of these two journals were calculated individually in Table 2, but they are treated as a single value in this article. The data for TAOS only cover those submissions from the atmospheric sciences (hereafter, TAOS-A). The data for $M Z$ excludes four special issues, primarily because these articles were invited or underwent "strict preselection" by the conference conveners before submission.

The data these journals self-reported were the total number of submissions in the most recent year data were available (2006 or 2007) and the total number of rejections. Some journals provided additional data to understand their reported data (e.g., number of manuscripts still out for review, number of manuscripts withdrawn by the author, the number of manuscripts rejected by the editor without undergoing peer review). Other information was collected about the journal, including whether the journal is published on a for-profit or nonprofit basis, whether published articles have page charges, and whether the journal's articles are open access (i.e., online articles are freely available to all). Some journals did not provide all the information requested. Nevertheless, the primary information I sought, the rejection rate (either directly reported by the journal or calculated from their data), was obtained for 47 out of the 63 journals surveyed (75\%).

The rejection rate of submissions is less than the ultimate success rate for manuscripts because manuscripts can be withdrawn by the author and rejected manuscripts can be revised and resubmitted to the same or to a different journal with the hope of eventually being published. For example, one-third of the manuscripts rejected from three astronomy journals (which had a $10 \%$ rejection rate) were eventually published (Abt 1988), and a metaanalysis of 15 studies of journals in a variety of scientific fields found that an average of $51 \%$ of rejected manuscripts were eventually published in journals different from the one to which it had originally been submitted (Weller 2001, p. 66). Although the rate at which rejected manuscripts eventually get published is not known precisely in the atmospheric sciences, based on my own experience and that of colleagues with whom I have talked, we estimate that about $20 \%$ of the rejected manuscripts in atmospheric science eventually get published.

Quantitative citation indices that allow journals to be compared (e.g., impact factor, immediacy index, half-life) come from ISI in 2006 (unless noted otherwise). (The sidebar entitled "Citation indices" has the definitions of these quantities.) Impact factor is perhaps the most widely used of those indices, a measure of how often the average article in the journal gets cited in a given year. For some people, the impact factor is 
TABLE 2. Rejection rates for atmospheric science journals. Unless otherwise stated in the text, these numbers exclude manuscripts withdrawn from the review process by the author or manuscripts transferred to other journals. The number of submissions is a I2-month value from 2006 or 2007, except that AR's values are for Feb 2006 to Mar 2008; AO, EJSSM, NWD, and TAOS-A combine 2006 and 2007; and JFM's rejection rate is a $10-y r$ average. The values for BAMS include proposal and manuscript submissions.

\begin{tabular}{|c|c|c|c|}
\hline Journal name & Acronym & Number of submissions & Rejection rate (\%) \\
\hline Advances in Atmospheric Science & AAS & 198 & 50.5 \\
\hline Atmospheric Chemistry and Physics & $A C P$ & 593 & 12.3 \\
\hline Atmospheric Environment & $A E$ & 1514 & 46.0 \\
\hline Atmosphere-Ocean (Combined) & $A O$ & 64 & 30.9 \\
\hline Atmosphere-Ocean (Atmosphere) & $A O-A$ & 42 & 22.2 \\
\hline Atmosphere-Ocean (Ocean) & $A O-O$ & 22 & 47.4 \\
\hline Atmospheric Research & $A R$ & 441 & 62.5 \\
\hline Atmospheric Science Letters & ASL & 77 & 40.3 \\
\hline Australian Meteorological Magazine & AMM & 28 & 44.0 \\
\hline Boundary-Layer Meteorology & $B-L M$ & 161 & 37.9 \\
\hline Bulletin of the American Meteorological Society & BAMS & 194 & 37.1 \\
\hline Climate Dynamics & $C D$ & 229 & 27.1 \\
\hline Climatic Change & CC & 228 & 39.9 \\
\hline Dynamics of the Atmosphere and Ocean & DAO & Not reported & 50.0 \\
\hline Electronic Journal of Operational Meteorology & EJOM & 18 & 44.4 \\
\hline Electronic Journal of Severe Storms Meteorology & EJSSM & 16 & 25.0 \\
\hline Environmental Fluid Mechanics & EFM & 81 & 45.7 \\
\hline Geophysica & G & 6 & 16.7 \\
\hline Geophysical Research Letters & GRL & $\sim 3800$ & 59.2 \\
\hline Global Biogeochemical Cycles & $G B C$ & $\sim 230$ & 57.4 \\
\hline International Journal of Biometeorology & IJB & 88 & 39.8 \\
\hline International Journal of Meteorology & IJM & 43 & 2.4 \\
\hline Journal of Aerosol Science & JAerS & 257 & 57.6 \\
\hline Journal of the Air \& Waste Management Association & JAWMA & 256 & 37.6 \\
\hline
\end{tabular}

a measure of journal importance or prestige-articles published in high-impact factor journals are more likely to be read and cited by others. Despite (or perhaps because of) its popularity, the impact factor has engendered and will likely continue to engender debate about its overemphasis and misuses (e.g., Cronin 2005; Garfield 2006; Wilson 2007; Campbell 2008; Todd and Ladel 2008; Archambault and Larivière 2009). As two examples, some scientists place considerable emphasis on publishing in a high-impact-factor journal, and some tenure and departmental ranking decisions are made with an eye toward impact factor. The purpose of this article is not to debate these issues, but to use these citation indices as broad measures of the journal volume and quality.

This present study is limited to addressing rejection rates for a 1-yr period for most journals. Therefore, a valid question is how representative this one year of data can be because of changes in the editorial board, journal policy, or the quality and number of submissions. For well-established journals with a large number of submissions each year (say, more than 50), there is little evidence that large changes in rejection rates occur on a year-to-year basis or longer (Weller 2001, 60-62). Over a 15-yr period, Hargens (1988) found the same result for 30 different journals in different fields, and JFM's rejection rate of 52\% (Table 2) is not substantially different from the $53 \%$ quoted by Batchelor (1981) over $20 \mathrm{yr}$ earlier. Given the rapid changes occurring in scientific publishing (e.g., online availability, the open-access movement, new journals being created) and the growing number of submissions from authors in developing countries (e.g., Mély et al. 1998; Holmgren and Schnitzer 2004; Leydesdorff and Zhou 2005; Zhou and Leydesdorff 2006), this present study should best be considered a snapshot 
TABLE 2. Continued.

\begin{tabular}{|c|c|c|c|}
\hline Journal name & Acronym & Number of submissions & Rejection rate (\%) \\
\hline Journal of Applied Meteorology and Climatology & JAMC & 262 & 32.1 \\
\hline Journal of Atmosphere and Ocean Technology (Combined) & JAOT & 227 & 21.1 \\
\hline Journal of Atmosphere and Ocean Technology (Atmosphere) & JAOT-A & 154 & 16.2 \\
\hline Journal of Atmosphere and Ocean Technology (Ocean) & JAOT-O & 73 & 31.5 \\
\hline Journal of Atmospheric Science & JAtmS & 399 & 26.8 \\
\hline Journal of Climate & $J C$ & 534 & 31.3 \\
\hline Journal of Fluid Mechanics & JFM & 877 & 52.0 \\
\hline Journal of Geophysical Research-Atmospheres & JGR-Atm & $\sim 1380$ & 29.7 \\
\hline Journal of Hydrometeorology & $J H$ & 145 & 38.6 \\
\hline Journal of Physical Oceanography & JPO & 255 & 18.8 \\
\hline Meteorological Applications & MA & 65 & 47.4 \\
\hline Meteorologische Zeitschrift & $M Z$ & 23 & 60.9 \\
\hline Meteorology and Atmospheric Physics & MAP & 140 & 59.2 \\
\hline Monthly Weather Review & MWR & 409 & 33.7 \\
\hline National Weather Digest & NWD & 24 & 25.0 \\
\hline Natural Hazards & $\mathrm{NH}$ & 210 & 35.2 \\
\hline Natural Hazards and Earth System Science & NHESS & 186 & 10.2 \\
\hline Nature & Nature & 9847 & 91.5 \\
\hline Ocean Modelling & $O M$ & 87 & 37.9 \\
\hline Physical Geography & PG & 95 & 68.4 \\
\hline Quarterly Journal of the Royal Meteorological Society & QJRMS & 212 & 26.4 \\
\hline Radio Science & RS & $\sim 200$ & 25.0 \\
\hline Space Weather & SW & $\sim 73$ & 52.1 \\
\hline Terrestrial, Atmospheric and Oceanic Sciences (Atmosphere) & TAOS-A & 40 & 50.0 \\
\hline Theoretical and Applied Climatology & TAC & 103 & 45.6 \\
\hline Weather and Forecasting & WAF & 135 & 27.4 \\
\hline Unnamed & Unnamed & 120 & 9.1 \\
\hline
\end{tabular}

in time. Results in $5 \mathrm{yr}$ are not likely to be different, but results in 10 or $20 \mathrm{yr}$ may be somewhat different.

Another limitation to this study relates to one of the most obvious reasons for rejection rates: journals with high rejection rates receive lower-quality submissions. Because no quantitative way exists to judge the quality of the science of published articles beyond the citation indices, and no way exists to judge the quality of submitted manuscripts, such an argument cannot be tested using the data in this study.

REJECTION RATES. Figure 1 shows the distribution of rejection rates (without withdrawals and transfers) for the 47 journals. The distribution of rejection rates ranges from $2 \%$ (IJM) to $91 \%$ (Nature; see Table 2). After Nature, the highest rejection rates are $P G(68 \%), A R(63 \%)$, and $M Z$ (61\%). The mean of the rejection rates for the 47 journals is $38.7 \%$. Excluding the outlier Nature, the remaining 46 journals have a mean rejection rate of $37.6 \%$, median of $37.9 \%$, and mode of $37 \%$, indicating the distribution has little skewness $(-0.16)$. In addition, the data are reasonably packed around the mean with most rejection rates ( 37 of the 46 journals, or $79 \%$ ) being between $25 \%$ and $60 \%$.

Journals with low rejection rates include IJM (2\%), Unnamed (9\%), NHESS (10\%), and ACP (12\%). IJM joins EJSSM, G, and NWD, a group of journals with relatively few yearly submissions (less than 50 ) that reject only a few manuscripts a year. The low rejection rates of these journals with a low number of submissions may be a result of "striving to improve received submissions and grow the journal" (EJSSM editor Roger Edwards 2009, personal communication). At $G$, editor Matti Leppäranta (2009, personal communication) notes that the low rejection rate is partially 


\section{CITATION INDICES}

The following are definitions of the citation indices developed by ISI and used in this article:

Impact factor: The impact factor for Journal $X$ for 2006 is the total number of citations in 2006 to articles in Journal $X$ published in the previous two years (2004 and 2005) divided by the number of articles in Journal $X$ published in the previous two years (2004 and 2005). A higher impact factor means more citations to articles in the journal, which many scientists believe is a measure, albeit a controversial one, of journal prestige or quality.

Half-life: The cited half-life for 2006 is the number of publication years back from 2006 that account for $50 \%$ of the citations. A longer half-life means that more of the citations come from older articles, which might indicate some measure of longevity of the research results.

mmediacy index: The immediacy index for 2006 is the number of citations to articles published in 2006 in Journal $X$ divided by the number of articles published in 2006 in Journal $X$. A higher immediacy index means that articles in the journal are cited more rapidly after being published, which might indicate a measure of a "hot" research field with eagerly anticipated and citable new results.

because some articles are "semi-invited" because of a "high national significance."

Another factor is that ACP, EJOM, EJSSM, and $N W D$ either encourage or enforce nonanonymous reviews, which some studies have shown makes reviewers less likely to recommend rejection (e.g., Walsh et al. 2000). Although van Rooyen et al. (1999) showed that rejection rates were not different whether or not the reviewer is anonymous, potential reviewers were $12 \%$ more likely to decline an invitation to review if their names were to be known to the authors.

The low rejection rate of Unnamed occurs because of a unique situation among the journals surveyed. When an editor wishes to reject a manuscript, the whole editorial board discusses the situation before a final decision is rendered. Before such a measure, however, editors sometimes encourage withdrawal by the author (possibly with revisions and resubmission) rather than face rejection by the board. When withdrawals are included, this journal's rejection rate climbs to $30 \%$, which is more in line with the average rejection rate.

Interestingly, ACP and NHESS, with their healthy number of submissions (593 and 186, respectively, in 2007), stand out from among the rest of these journals with low rejection rates. Both are open- access journals published by the EGU. Explaining $A C P$ 's low rejection rate, chief executive editor and founder Ulrich Pöschl (2007 and 2008, personal communication) said, "The low rejection rates do not contradict the high quality standards of ACP. In fact, they confirm [the] high average quality of submitted manuscripts as expected from public peer review and interactive discussion." The reason for the low rejection rate is that "Interactive peer review and public discussion indeed deter deficient submissions and counteract the flooding of the scientific publication market" (Pöschl 2004). [The unique editorial concept behind ACP was foreshadowed by Segal et al. (1995) and is described by Pöschl $(2004,2009)$ and Koop and Pöschl (2006).] Indeed, that ACP has had the highest impact factor in atmospheric sciences since 2005 attests to this claim. Because of the success of this concept, EGU (in partnership with Copernicus Publications) is launching new open-access journals based on the ACP model.

One argument that has been offered for $A C P$ 's high impact factor is that the paper is exposed to public discussion, alerting the community of its impending publication, so other authors can begin citing the paper earlier than in a traditional journal. Indeed, $A C P$ does have the third highest immediacy index (after TAOS and JC). Given that the impact factor is calculated with a 2-yr window, this short time for citing the paper can be crucial to a journal achieving a high impact factor. Starting in 2007, ISI published an impact factor calculated over a 5 -yr window, as well.

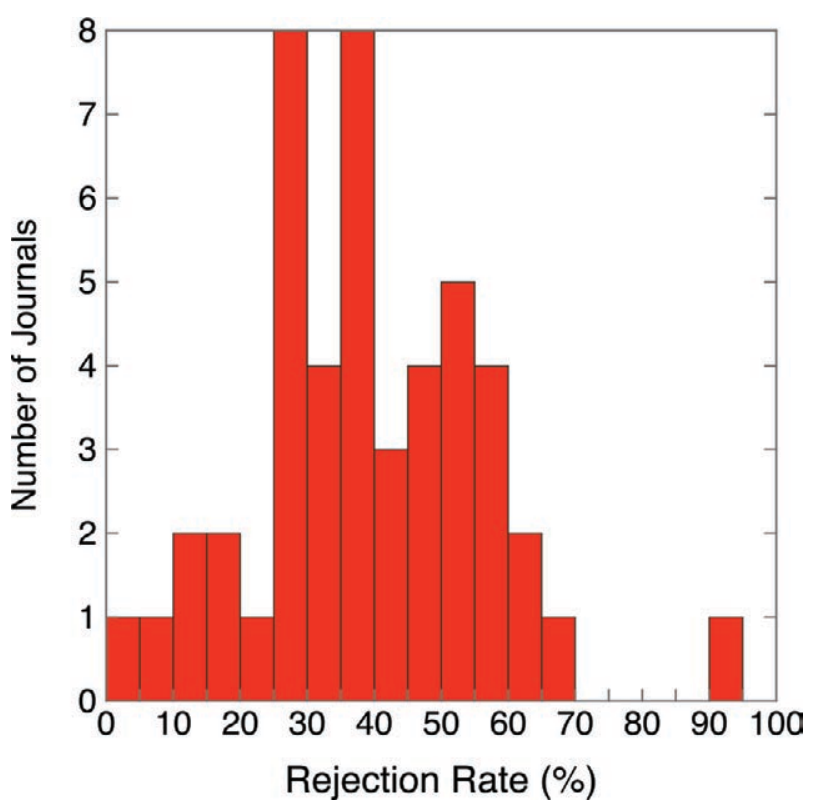

FIG. I. Histogram of rejection rates for $\mathbf{4 7}$ journals publishing in the atmospheric sciences. 
For the journals where both have been calculated, there is a high degree of correlation between the 2and 5-yr impact factor $(R=0.955)$, with $A C P$ having the third highest 5-yr impact factor (Fig. 2). Thus, although the longer exposure may be contributing to ACP's high impact factor, it is hard to argue that longer exposure is the dominant effect.

Another journal with an atypical editorial policy is $B A M S$, which requires that proposals for manuscripts be approved by the chief editor before manuscript submission. In 2006, 194 proposals were received, of which 43 proposals (22\%) were rejected and $20(10 \%)$ of the accepted proposals never had manuscripts submitted. In 2006, 131 manuscripts were received, of which 4 were rejected by the editor without peer review and 25 were rejected after peer review (a total of $22 \%$ ). Thus, a different rejection rate would be the sum of the rejected papers and rejected proposals divided by total proposal submissions (72/194), or 37\%. This $37 \%$ is the rejection rate for $B A M S$, appearing in Table 2 and used in this article.

REJECTION WITHOUT PEER REVIEW. Most submitted manuscripts undergo some kind of assessment by an editor before being sent out for peer review. In some cases, the editor may decide to summarily reject the manuscript without sending it to peer reviewers. Strong editorial control (as measured by summary rejections) serves two purposes. First, manuscripts on topics too far afield of the journal mission can be quickly handled, allowing the author to find a more appropriate journal without additional delay. Second, if the manuscript is of poor quality, the editor may save the valuable time and effort of peer reviewers. Out of 32 journals that addressed this issue of editor rejection without peer review, 21 (66\%) have rejected one or more manuscripts without sending the manuscripts to peer reviewers.

For example, the policy of JAerS is to recommend that papers that are either too weak to be published in JAerS or are not relevant to the journal be published elsewhere rather than be rejected. Thus, their high rejection rate (58\%) combines the two outcomes "reject" (21\%) and "publish elsewhere" (37\%; "withdraw" only accounts for $2 \%$ more). In another example, the manuscript proposals and strong editorial control at BAMS lead to $60 \%$ of the rejected proposals and manuscripts being rejected without review.

Nature and Science take this approach to the extreme. With over 10,000 manuscript submissions a year, Nature, with a 2008 rejection rate of $91.95 \%$ (up from $91.45 \%$ in 2006, and increasing every year as the number of submissions increases; information

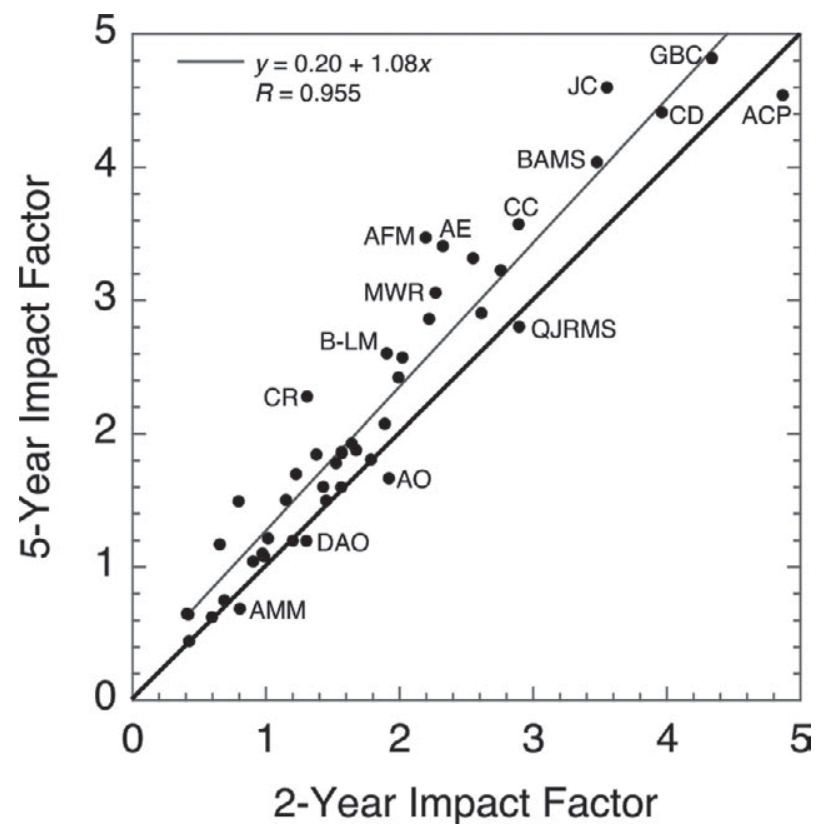

FIG. 2. Scatterplot of journals reporting both 2- and 5-yr impact factors for $\mathbf{2 0 0 7}$, with select journal abbreviations labeled. The I: I diagonal (thick black line) and the linear regression line $y=0.20+1.08 x$ with an $R$ of $\mathbf{0 . 9 5 5}$ (thin gray line) are shown. Journal abbreviations are listed in Table 2, except for Agricultural and Forest Meteorology (AFM) and Climate Research (CR).

online at www.nature.com/nature/authors/get published/index.html), admits to having "to decline many papers of very high quality but of insufficient interest to their specific readership" (www.nature. com/authors/author_services/about_nature_family. html). Similarly, Science says that, "priority is given to papers that reveal novel concepts of broad interest" (www.sciencemag.org/about/authors/prep/gen_info. $\mathrm{dt} l$ ), returning a large unstated fraction of submitted manuscripts to authors without peer review. Clearly, receiving such a large number of submissions from a large number of disciplines vying for a small number of printed pages requires heavy editorial pruning. Formal statistics on what percentage of rejected manuscripts were sent out for peer review was not available from Nature and Science, although over $20 \mathrm{yr}$ ago roughly $60 \%$ of the submitted manuscripts were rejected without peer review at Science, with 20\% eventually getting published and 20\% rejected after peer review (Koshland 1985).

Other journals where the ratio of the number of rejections without review to the total number of rejections is highest (for journals with more than five rejections) include ACP (79\%), JAerS (64\%), and PG (46\%). Eight journals have their ratios between $29 \%$ and $38 \%$ (AE, ASL, NWD, NH, NHESS, AMM, IJB, 
and EJOM). In contrast, other journals reject only a few, if any, manuscripts without peer review, many of which are published by the AMS.

WITHDRAWN MANUSCRIPTS. Of the 47 journals with known rejection rates, 33 (70\%) provided data on withdrawals by the author. Withdrawn manuscripts may happen because the editor encourages the author to withdraw the manuscript (e.g., for resubmission after revisions or submission to a different journal, in lieu of rejection), the author is overwhelmed (e.g., by the revisions, extended travel, death in the family), the author is unable to revise the manuscript within a reasonable time, or the author is unhappy with the review process. The highest withdrawal rate is from Unnamed (30\%), where withdrawal is encouraged by the editors rather than rejection. $M Z$ has a $17 \%$ withdrawal rate, but this is the result of only four manuscripts. BAMS proposals have a high withdrawal rate (15\%) because subsequent manuscripts may not always result from the proposal. The remaining journals all have withdrawal rates of $12 \%$ or less, with most less than $10 \%$. For this reason, subsequent analyses in this article are not qualitatively different whether or not the withdrawal rate is added to the rejection rate. Consequently, to use the larger 47-member dataset in this study instead of the reduced 33-member dataset, the withdrawals are not included in further analysis.

\section{JOURNAL VOLUME AND CITATION}

INDICES. The relationships between rejection rates and quantitative measures of the journal volume and quality are explored in Fig. 3, which omits Nature, an outlier in rejection rate (91\%), number of citations (over 390,000), number of submissions (around 10,000), impact factor (26.7), and immediacy index (6.8). Most of these indices (i.e., the number of published articles, number of citations, impact factor, and half-life) are not related to rejection rate (Figs. 3b,c,d,f). Nevertheless, journals with higher rejection rates do tend to have more submissions (Fig. 3a) and lower immediacy indices (Fig. 3e), although these relationships are quite weak. If measures of volume and quality are unrelated to rejection rate, then what about measures of the business model of the journal (for profit/nonprofit, page charges, and open access)?

FOR-PROFIT VERSUS NONPROFIT JOURNALS. The line between for profit and nonprofit may be a fine one because some professional societies make money from their publications. For example, the nonprofit AMS earned a surplus of
$\$ 400,000$ on journals in 2005 (Jorgensen et al. 2007). In addition, some professional societies use Web sites of commercial publishers for access to their published archives. For example, the Royal Meteorological Society (RMS) hires commercial publisher WileyBlackwell to publish ASL, IJC, MA, and QJRMS (e.g., Thuburn and Baldwin 2008).

There are about 23,000 peer-reviewed journals in science, technology, and medicine that publish 1.4 million articles a year (Springer Science + Business 2007 Annual Report). Two of the biggest commercial publishers are Springer and Elsevier, with Springer publishing 2,000 journals with a $9 \%$ market share (measured by the number of articles published) and Elsevier publishing 1,100 journals with a $14 \%$ market share. Indeed, 8 (17\%) of the 47 journals reporting rejection rates and $10(16 \%)$ of the 63 journals in the whole dataset are published by Springer, and 5 (11\%) of the 47 and 8 (13\%) of the 63 are published by Elsevier. Other major publishers in this 63-member dataset include the AMS (9.5 journals), AGU (5.5), RMS (4), and EGU (3). [Earth Interactions counts as half a journal each for AMS and AGU.]

Interestingly, of the 46 journals with rejection rates (excluding Nature), 18 (95\%) of the 19 journals with the lowest rejection rates (less than 34\%) are nonprofit. Of the remaining 27 journals with the highest rejection rates, 13 (48\%) are nonprofit. The means of the rejection rates are $33 \%$ for the 31 nonprofit journals and $48 \%$ for the 15 for-profit journals, a result that is highly statistically significant $(p<0.01$ using Student's $t$ test). Thus, journals published to make a profit tend to have higher rejection rates. Although nonprofit journals have higher impact factors than for-profit journals (means of 1.87 versus 1.72), the result is not statistically significant, a result that differs from economics journals where the most-cited journals are overwhelmingly nonprofit (Bergstrom 2001; Greco et al. 2006).

PAGE CHARGES. There are two ways to finance scientific publications: pay to put something in the journal (e.g., advertisement or article) or pay to read it (e.g., individual or library subscription or pay to read individual articles online). (A third approach is to get external money to maintain the journal through grants or patrons, although little information is known about this for most journals.) The journals surveyed in this article have both extremes represented. On the one hand, ACP, EJSSM, EJOM, and NHESS only assess page charges, the price authors pay to publish their articles. (In practice, mostly the author's institutions or funding agencies pay the page 

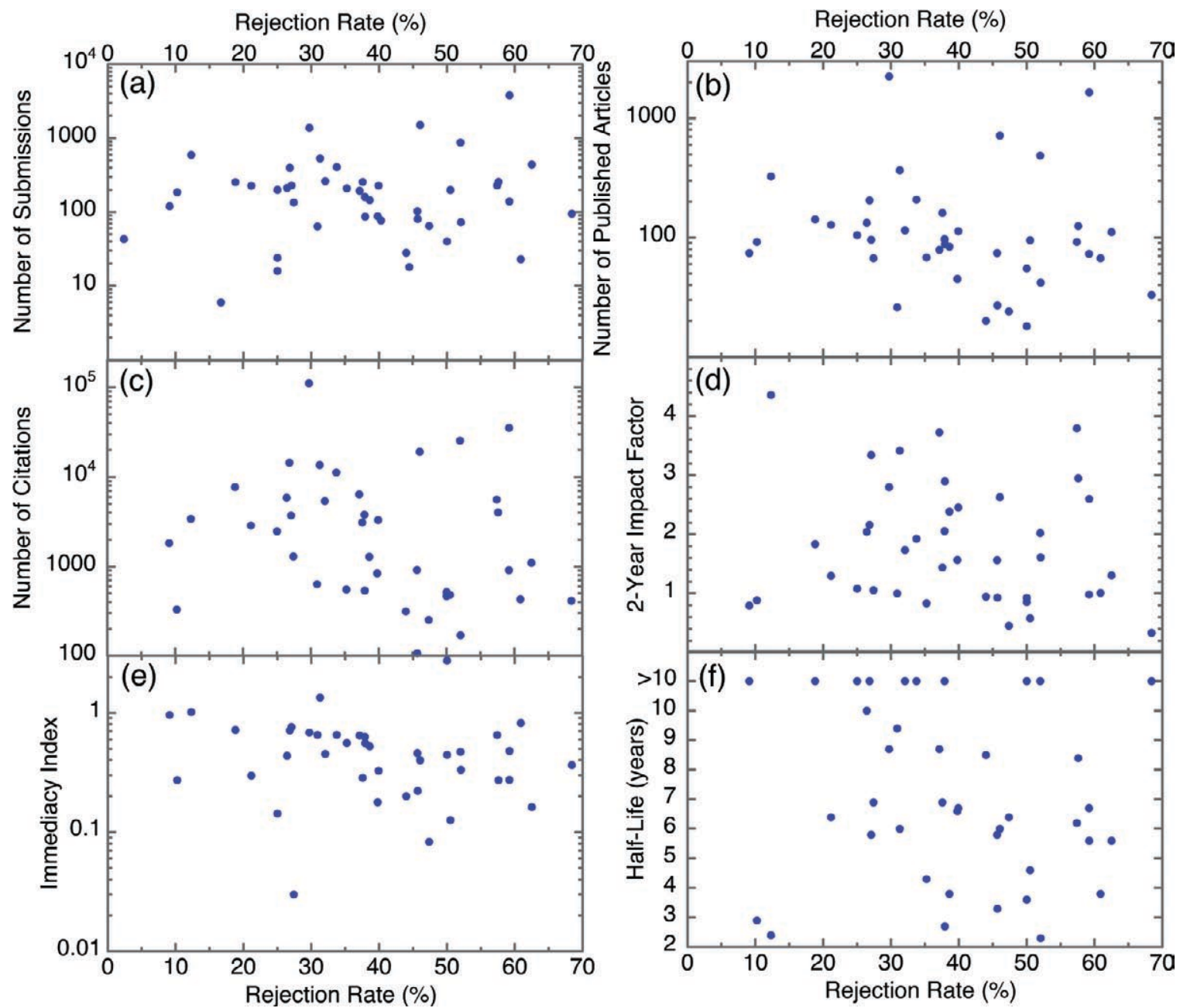

FIG. 3. Rejection rate (\%) versus various citation indices: (a) number of self-reported submissions (2006 or 2007), (b) number of published articles, (c) number of citations, (d) 2-yr impact factor, (e) immediacy index, and (f) half-life (yr). All indices except (a) are from ISI in 2006. Nature is excluded from these plots. The number of points in each panel is 40 , except for (a), with 45 points.

charges, although members of the National Weather Association publish in EJOM for free.) Once an article is published, it is free to view online and download (open access). On the other hand, there are 21 journals where accepted manuscripts are published for free (i.e., no page charges), but readers either pay to view or download the paper online or pay through their libraries' or individual's subscriptions to the journal (either paper or online subscriptions). Other journals have both page charges and subscription fees.

Of the 47 journals where the rejection rate is known, 46 could be ascertained to have or not have page charges. Of these 45 journals (excluding Nature), 22 (49\%) have no page charges for manuscripts without color figures, and these journals have higher rejection rates (mean of $42 \%$ ) than those with page charges (mean of $32 \%$ ), a result that is statistically significant ( $p=0.027$, using Student's $t$ test).
Journals with page charges and lower rejection rates do not appear to imply lower impact factors. Although the impact factor is slightly higher for journals with page charges (1.97 versus 1.68), the difference is not statistically significant.

Given that both nonprofit journals and those with page charges are related to lower rejection rates, a reasonable question to ask is about the relationship between these two. Of nonprofit journals, 11 have no page charges and 25 have page charges. Of for-profit journals, 17 have no page charges and only 3 have page charges (none report rejection rates), showing a remarkable degree of consistency among for-profit journals and no page charges, but less so among nonprofits and page charges. For the nonprofit journals, the difference between rejection rates for journals with and without page charges (32\% and 34\%, respectively) is not statistically significant. 
OPEN-ACCESS JOURNALS. Open-access journals make their content available online for free to everyone by shifting the cost of publishing from the reader to the author. Some journals have provided an open-access option for published articles through an extra fee added to any page charges (e.g., Springer has Open Choice, AGU has Author Choice). The AMS offers a different model, making the archives of all journal articles older than five years after publication open access through the Legacy Project (e.g., Seitter 2002; Jorgensen et al. 2007, p. 1134). (As of 1 January 2010, the AMS journal archives are now open access after two years.)

As of the writing of this article (September 2009), the Directory of Open Access Journals (www.doaj. org) listed 20 journals in the category of "Meteorology and Climatology," many of which are published by professional societies or universities. Four of these journals are included in this dataset: $A C P, E J O M$, EJSSM, and NHESS, plus BAMS (whose scientific content is freely available online). $A C P$ is the journal with the highest impact factor in the atmospheric sciences with nearly 600 submissions a year, BAMS is typically in the top three in impact factor with nearly 200 submissions a year (including proposals), and NHESS is 39th in impact factor (albeit only published since 2001) with nearly 200 submissions a year. In contrast, the other two journals (EJOM and EJSSM) are unranked and had fewer than 25 submissions each. The rejection rates for open-access journals were relatively low, with $A C P$ 's rejection rate at $16 \%, E J S S M$ 's at $25 \%$, and NHESS's at $10 \%$. EJOM welcomed a new editorial board in 2007 , and that board has been more selective, rejecting 8 (44\%) out of 18 submissions. For comparison, during 11 months in 2006, EJOM rejected 3 out of 14 submissions for a $21 \%$ rejection rate.

\section{CONSENSUS IN THE ATMOSPHERIC} SCIENCES. Based on the results of this article, atmospheric science has some degree of consensus, defined as the shared conceptions of research problems and techniques within the discipline (Hargens 1988). Several pieces of evidence support this statement.

Seventy-nine percent of journals have rejection rates of $25 \%-60 \%$. If a larger percentage of journals had rejection rates that were very low or very high, then arguing that consensus exists within the atmospheric science community would be more difficult.

In 2006, the eight scientific journals published by the AMS (JAOT, JAMC, JAtmS, JC, JH, JPO, MWR, and WAF) rejected 685 manuscripts out of 2353 sub- missions, or $29 \%$. Rejection rates for individual journals do not show much spread from this average value, ranging from $19 \%$ to $39 \%$ (Table 2), and rejection rates at these journals have been relatively constant over time (AMS Publications Commissioner D. Jorgensen 2008, personal communication). These journals are a subset where consensus would be expected to be high because the peer-review process is uniform. Thus, $20 \%$ might be considered to be a typical value of the variability in rejection rates that can be expected for a given publisher or publishing model.

Even among journals that cater to a certain discipline, but are published by different publishers with different publishing models, consensus appears to be quite high. Specifically, the four journals for operational forecasters (i.e., EJOM, EJSSM, NWD, and $W A F$ ) have rejection rates of $44 \%, 25 \%, 25 \%$, and $27 \%$, respectively. (EJOM's $44 \%$ rejection rate was $21 \%$ in the previous year.) In contrast, a more varied discipline exhibits a larger range in rejection rates with the four journals for oceanography (i.e., $A O-O$, $J A O T-O, J P O$, and $O M$ ) having rejection rates of $47 \%$, $31.5 \%, 18.8 \%$, and $37.9 \%$, respectively.

Moreover, the rejection rates of these four journals for forecasters fit comfortably within the range of the rest of the other journals. This result might be surprising, given the differences in learning styles between forecasters and researchers (Roebber 2005; Stuart et al. 2007) and that forecasters tend to publish less, indicating less likelihood of consensus between forecasters and researchers (e.g., Rossby 1934; Bergeron 1959; Doswell et al. 1981).

That few journals have rejection rates smaller than $25 \%$ indicates that a universal minimum standard of quality for published manuscripts seems to exist. Although quantitative assessment of the quality of manuscripts is not simple, editorial experience indicates that most rejections at journals with less vigorous editorial control are poor-quality manuscripts unworthy of publication. Manuscripts so pioneering, unique, or controversial that they fail to gain acceptance during the review process (as might be the case were consensus not present) are rare, a point noted by Batchelor $(1981,15-17)$ for JFM.

\section{CONCLUSIONS, CAUTIONS, AND CONTEMPLATIONS. Although consensus} within the atmospheric sciences helps to limit the range of rejection rates across the journals, it cannot explain the variability in rejection rates. The results in this article indicate that journal volume and quality (as measured by the citation indices) are not strongly related to rejection rate, a result also found 
by Coe and Weinstock (1983) for journals in the finance community and by Weller (2001, p. 71) in her synthesis of the literature. Instead, the results in this article reveal that the variability of rejection rates is most strongly related to the journal's business model: whether the journals are for profit or nonprofit, and whether they assess page charges. For-profit journals have higher rejection rates than nonprofit journals. Because for-profit journals are overwhelmingly free of page charges, they may be highly sought after by authors seeking low-cost options for publication, leading to high rejection rates. Other for-profit journals are even more selective, publishing only the highest-quality manuscripts or manuscripts with a great interest to other scientists or the general public (i.e., newsworthiness). Zuckerman and Merton (1971, p. 92) summarize these selective journals' philosophy as simply, "When in doubt, reject."

On the other hand, journals published by professional societies and other nonprofits have lower rejection rates. These journals may be less likely to be restrictive by publishing manuscripts that are both relevant to the journal and that meet a minimum level of scientific quality, either for the benefit of the professional society or for the science itself. Another contributing factor is that because page charges tend to be assessed by nonprofit journals (69\% of nonprofit journals collect page charges), only authors with research grants or access to resources through their institutions can afford to publish in these journals. As such, these manuscripts may be of higher quality because of the authors' abilities to secure research grants or pass internal peer review. Interestingly, nonprofit journals without page charges have rejection rates that are statistically indistinguishable from nonprofit journals with page charges.

Two cautions are worth stating. First, strong statistical relationships are not evidence of causative relationships. Thus, although we can make reasoned arguments about why there might be a link between the journal's business model and its rejection rates, it is not clear exactly how, or even if, the business practices of the publisher filter down to the day-to-day mechanics of decision making by editors. In fact, the decisions made by authors of where to submit their manuscripts may represent the principal factor in rejection rates, as discussed earlier. The results of this study, although suggestive, leave the exact mechanism that would act across a wide range of journals indeterminate through these statistical approaches on the dataset collected for this study.

Second, the results of this study should not be used as a menu for authors to decide to which journals to target their submitted manuscripts. Many factors go into the decision of where to submit a manuscript, such as relevance to the journal and audience, format or length of article, open access, urgency to publish the results, page charges, and the ability to include color figures and animations (e.g., Schultz 2009b, section 2.3). However, this study focuses on one minor aspect only-rejection rate. More important aspects need to be considered when selecting a target journal.

Finally, consider the statistics in this article. At least 6,106 manuscripts were rejected in one year by the 46 journals in Table 2 (excluding Nature), including 542 that are rejected by the editors without undergoing peer review. Although some of these manuscripts will eventually be successful (pending revisions to improve the manuscript, resubmission, and publication), many will not be. Therefore, a fraction of manuscripts written by authors, many of whom have spent years in graduate school pursuing advanced degrees and may be professors at colleges and universities instructing others how to do science, may not be able to perform high-quality science, communicate effectively, or both. Although many poor-quality manuscripts are prevented from being published, some would argue that peer review does not go far enough in weeding out poor-quality science (e.g., Errico 2000) and even instances of scientific misconduct (e.g., Wu et al. 2004; International Journal of Remote Sensing 2006). The changing landscape of scientific publishing offers new opportunities for innovative models in journal peer review, management, dissemination, and financing that will have to address the issues raised by this study in order to maintain and improve the quality of scientific publications.

ACKNOWLEDGMENTS. I thank all those who provided data from and information on their journals. With their strong support and commitment, this study had a remarkable 75\% participation rate. Data in Table 2 and the manuscript come from the following sources: David Jorgensen (2007 Publications Commission Report for all AMS journals except $B A M S)$, Robert Rauber (JAMC), Ka-Kit Tung (JAS), Nick Shay (JAOT), Andrew Weaver $(J C)$, Ana Barros (JH), Peter Muller (JPO), Harold Brooks and David Stensrud (WAF), Shi Aolan, Zhou Ling, and Da-Lin Zhang ( $A A S)$, Ulrich Pöschl $(A C P)$, Karen Sturges $(A E)$, Andrew Hollis $(A M M)$, Andrew Bush and Denis Gilbert ( $A O)$, Andrea Flossmann, Clive Saunders, and John Snow $(A R)$, Alison Hunter (ASL, MA, QJRMS), Alan Gadian ( $A S L)$, Jeff Waldstreicher (BAMS), John Garratt $(B-L M)$, Katarina Kivel (CC), Edwin Schneider 
$(C D)$, Marloes de Jong (DAO), Benoit Cushman-Roisin (EFM), Matthew Bunkers and Jeff Craven (EJOM), Roger Edwards (EJSSM), Matti Leppäranata $(G)$, Scott Sheridan (IJB), Samantha Hall (IJM), Nancy Bernheisel (JAWMA), Gerhard Kasper (JAerS), Linda Drath (JFM), Reinhold Steinacker (MAP), Stefan Emeis $(M Z)$, Ayrene Dialogo $(N H)$, Natascha Töpfer and Fausto Guzzetti (NHESS), Gary Ellrod and Peter Roohr (NWD), Maxine Clark (N), the late Peter Killworth $(O M)$, Antony Orme $(P G)$, Louis Lanzerotti $(S W)$, Chun-Chieh Wu (TAOS-A), and Harmut Graßl (TAC). Thanks to the following individuals for their comments on earlier versions of this manuscript: Mark Baldwin, Matthew Bunkers, Benoit Cushman-Roisin, Gary Ellrod, Branko Grisogono, Lowell Hargens, David Jorgensen, Gerhard Kasper, Ulrich Pöschl, Paul Roebber, Edwin Schneider, Keith Seitter, Jeff Waldstreicher, and two anonymous reviewers. Partial funding for Schultz comes from Vaisala Oyj. Schultz serves on the editorial boards of four journals: Chief Editor of $M W R$, Assistant Editor and cofounder of EJSSM, Associate Editor of ASL, and a member of the editorial board of $G$.

\section{REFERENCES}

Abt, H. A., 1988: What happens to rejected astronomical papers? Publ. Astron. Soc. Pac., 100, 506-508.

Archambault, É., and V. Larivière, 2009: History of the journal impact factor: Contingencies and consequences. Scientometrics, 79, 635-649.

Bakanic, V., C. McPhail, and R. J. Simon, 1987: The manuscript review and decision-making process. Amer. Sociol. Rev., 52, 631-642.

Batchelor, G. K., 1981: Preoccupations of a journal editor. J. Fluid Mech., 106, 1-25.

Bergeron, T., 1959: Weather forecasting: Methods in scientific weather analysis: An outline in the history of ideas and hints at a program. The Atmosphere and the Sea in Motion, B. Bolin, Ed., The Rockefeller Institute Press, 440-474.

Bergstrom, T. C., 2001: Free labor for costly journals? J. Econ. Perspect., 15(3), 183-198.

Campbell, P., 2008: Escape from the impact factor. Ethics Sci. Environ. Politics, 8, 5-7.

Coe, R. K., and I. Weinstock, 1983: Evaluating the finance journals: The department chairperson's perspective. J. Financ. Res., 6, 345-349.

Cronin, B., 2005: A hundred million acts of whimsy? Curr. Sci., 89, 1505-1509.

Day, R. A., and B. Gastel, 2006: How to Write and Publish a Scientific Paper. 6th ed. Cambridge University Press, 302 pp.

Doswell, C. A. III, L. R. Lemon, and R. A. Maddox, 1981: Forecaster training-A review and analysis. Bull.
Amer. Meteor. Soc., 62, 983-988.

Drummond, C. W. E., and D. S. Reeves, 2005: Reduced time to publication and increased rejection rate. $J$. Antimicrob. Chemother., 55, 815-816.

Errico, R. M., 2000: On the lack of accountability in meteorological research. Bull. Amer. Meteor. Soc., 81, 1333-1337.

Famiglietti, J. S., 2007: Editorial-Geophysical Research Letters: New policies and features for AGU's top-cited journal. Eos, Trans. Amer. Geophys. Union, 88, 537.

Garfield, E., cited 2005: The agony and the ecstasy-The history and meaning of the journal impact factor. [Available online at www.garfield.library.upenn.edu/ papers/jifchicago2005.pdf.]

— 2006: The history and meaning of the journal impact factor. J. Amer. Med. Assoc., 295, 90-93.

Greco, A. N., R. M. Wharton, H. Estelami, and R. F. Jones, 2006: The state of scholarly journal publishing: 1981-2000. J. Scholarly Publ., 37, 155-214.

Hargens, L. L., 1988: Scholarly consensus and journal rejection rates. Amer. Sociol. Rev., 53, 139-151.

Holmgren, M., and S. A. Schnitzer, 2004: Science on the rise in developing countries. PLoS Biol., 2, 10-13.

International Journal of Remote Sensing, 2006: Statement of retraction. Int. J. Remote Sens., 27, 3749-3750.

Jorgensen, D. P., R. M. Rauber, K. F. Heideman, M. E. Fernau, M. A. Friedman, and A. L. Schein, 2007: The evolving publication process of the AMS. Bull. Amer. Meteor. Soc., 88, 1122-1134.

Koop, T., and U. Pöschl, cited 2006: Systems: An open, two-stage peer-review journal. Nature, doi:10.1038/ nature04988. [Available online at www.nature.com/ nature/peerreview/debate/nature04988.html.]

Koshland, D. E., 1985: An editor's quest (II). Science, 227, 249.

Leydesdorff, L., and P. Zhou, 2005: Are the contributions of China and Korea upsetting the world system of science? Scientometrics, 63, 617-630.

Lipton, W. J., 1998: The Science Editor's Soapbox. Science Soapbox, 93 pp.

Mély, B., M. A. El Kader, G. Dudognon, and Y. Okubo, 1998: Scientific publications of China in 1994: Evolution or revolution? Scientometrics, 42, 3-16.

Miller, A. C., and S. L. Serzan, 1984: Criteria for identifying a refereed journal. J. Higher Educ., 55, 673-699.

Montgomery, S. L., 2003: The Chicago Guide to Communicating Science. University of Chicago Press, $228 \mathrm{pp}$.

Opthof, T., R. Coronel, and M. J. Janse, 2002: The significance of the peer review process against the background of bias: Priority ratings of reviewers and editors and the prediction of citation, the role of geographical bias. Cardiovasc. Res., 56, 339-346. 
Perelman, L. C., J. Paradis, and E. Barrett, 1998: The Mayfield Handbook of Technical \& Scientific Writing. Mayfield Publishing, 508 pp. [Available online at http://web.mit.edu/writing/temp2/home.htm.]

Pöschl, U., 2004: Interactive journal concept for improved scientific publishing and quality assurance. Learned Publ., 17, 105-113.

— 2009: Interactive open access peer review: The Atmospheric Chemistry and Physics model. Against the Grain, 21(3), 26-32.

Roebber, P. J., 2005: Bridging the gap between theory and applications: An inquiry into atmospheric science teaching. Bull. Amer. Meteor. Soc., 86, 507-517.

Rossby, C.-G., 1934: Comments on meteorological research. J. Aeronaut. Sci., 1, 32-34.

Schultz, D. M., 2009a: Are three heads better than two? How the number of reviewers and editor behavior affect the rejection rate. Scientometrics, doi:10.1007/ s11192-009-0084-0, in press.

—, 2009b: Eloquent Science: A Practical Guide to Becoming a Better Writer, Speaker, and Atmospheric Scientist. Amer. Meteor. Soc., 440 pp.

Segal, M., R. Turner, and D. Yarger, 1995: On scientific electronic journals and conferences. Bull. Amer. Meteor. Soc., 76, 2245-2246.

Seitter, K. L., 2002: Opening access to the AMS Journals Online. Bull. Amer. Meteor. Soc., 83, 1361.

Siegelman, S. S., 1991: Assassins and zealots: Variations in peer review. Radiology, 178, 637-642.

Stuart, N. A., D. M. Schultz, and G. Klein, 2007: Maintaining the role of humans in the forecast process:
Analyzing the psyche of expert forecasters. Bull. Amer. Meteor. Soc., 88, 1893-1898.

Thrower, P. A., 2007: Writing a scientific paper: I. Titles and abstracts. Carbon, 45, 2143-2144.

Thuburn, J., and M. Baldwin, 2008: Recent and future changes to the Quarterly Journal. Quart. J. Roy. Meteor. Soc., 134, 1949.

Todd, P. A., and R. J. Ladel, 2008: Hidden dangers of a 'citation culture.' Ethics Sci. Environ. Polit., 8, 13-16.

van Rooyen, S., F. Godlee, S. Evans, N. Black, and R. Smith, 1999: Effect of open peer review on quality of reviews and on reviewers' recommendations: A randomised trial. Br. Med. J., 318, 23-27.

Walsh, E., M. Rooney, L. Appleby, and G. Wilkinson, 2000: Open peer review: A randomised controlled trial. Br. J. Psychiatry, 176, 47-51.

Weller, A. C., 2001: Editorial Peer Review: Its Strengths and Weaknesses. ASIST Monogr. Series, Information Today, $342 \mathrm{pp}$.

Wilson, A. E., 2007: Journal impact factors are inflated. Bioscience, 57, 551-552.

Wu, G., H. Wang, and D.-L. Zhang, 2004: Retraction and editorial statement. Adv. Atmos. Sci., 21, 382.

Zhou, P., and L. Leydesdorff, 2006: The emergence of China as a leading nation in science. Res. Policy, 35, 83-104.

Zuckerman, H., and R. K. Merton, 1971: Patterns of evaluation in science: Institutionalisation, structure and functions of the referee system. Minerva, 9, 66-100. 